\title{
Comparative Marker Analysis after Isolation and Culture of Testicular Cells from the Immature Marmoset
}

\author{
Silvia Albert ${ }^{a}$ Joachim Wistuba ${ }^{a}$ Katja Eildermann ${ }^{c}$ Jens Ehmcke ${ }^{a} b$ \\ Stefan Schlatt ${ }^{\mathrm{a}}$ Joerg Gromoll ${ }^{\mathrm{a}}$ Nina Kossack ${ }^{\mathrm{a}}$ \\ ${ }^{a}$ Center of Reproductive Medicine and Andrology, Institute of Reproductive and Regenerative Biology, and \\ ${ }^{b}$ Central Animal Facility of the Medical Faculty, Albert Schweitzer Campus 1, University of Münster, Münster, and \\ 'Stem Cell Biology Unit, German Primate Center, Göttingen, Germany
}

\section{Key Words}

Testis development $\cdot$ Germ cells $\cdot$ Sertoli cells $\cdot$ Peritubular cells $\cdot$ Marmoset monkey

\begin{abstract}
The marmoset monkey is a valuable model in reproductive medicine. While previous studies have evaluated germ cell dynamics in the postnatal marmoset, the features of testicular somatic cells remain largely unknown. Therefore, the aim of this study was to establish marmoset-specific markers for Sertoli and peritubular cells (PTCs) and to compare protocols for the enrichment and culture of testicular cell types. Immunohistochemistry of Sertoli and PTC-specific markers - antimüllerian hormone (AMH), vimentin (VIM), $\alpha$-smooth muscle actin (SMA) - was performed and corresponding RNA expression profiles were established by quantitative PCR analysis (SOX9, AMH, FSHR, VIM, and SMA). For these analyses, testicular tissue from newborn $(n=4), 8$-week-old $(n=4)$ and adult $(n=3)$ marmoset monkeys was used. Protocols for the enrichment and culture of testicular cell fractions from the 8-week-old marmoset monkeys $(n=3)$ were evaluated and cells were analyzed using germ cell- and somatic cell-specific markers. The expression of AMH, VIM and SMA reflects the proportion and differentiation status of Sertoli and PTCs at the RNA and the protein levels. While applied protocols did not support the propagation of germ cells in vitro, our analy-
\end{abstract}

ses revealed that PTCs maintain their proliferative potential and constitute the dominant cell type after short- and longterm culture. Expression of functionally meaningful testicular somatic markers is similar in the human and the marmoset monkey, indicating that this primate can indeed be used as model for human testicular development. The PTC culture system established in this study will facilitate the identification of factors influencing male sex differentiation and spermatogenesis.

Copyright $\odot 2012$ S. Karger AG, Basel

\section{KARGER}

Fax +4161306 1234

E-Mail karger@karger.ch

www.karger.com
(C) 2012 S. Karger AG, Basel

$1422-6405 / 12 / 1966-0543 \$ 38.00 / 0$

Accessible online at:

www.karger.com/cto
Dr. Nina Kossack

Center of Reproductive Medicine and Andrology

Albert Schweitzer Campus 1 (D11), University of Münster

DE-48149 Münster (Germany)

Tel. +492518357 365, E-Mail Nina.Kossack@ukmuenster.de 


\section{Introduction}

For the analysis of human testicular development, in vitro cultures of pure testicular cell populations from different developmental time points would be highly beneficial. These cultures would facilitate the identification of factors involved in male sex differentiation and would thereby provide new insights into the underlying causes of male infertility. However, for ethical and legal reasons, access to human testicular tissue is limited. Therefore, an animal model is required that resembles the human situation closely. Because of the remarkable differences concerning the spermatogonial stem cell systems between rodents and primates [Ehmcke et al., 2006], rodents are not appropriate. In rodent spermatogenesis, numerous spermatogonial divisions drive the mitotic spread of spermatogonia, thereby producing large clones originating from $\mathrm{A}_{\text {single }}$ spermatogonia, which cover the stem cell population that does not include reserve stem cells. In contrast, in primates, this mitotic spread is differently organized with only a few divisions of the active $A_{\text {pale }}$ spermatogonial stem cells. In addition, these active stem cells are backed up by a population of reserve stem cells, namely the $\mathrm{A}_{\text {dark }}$ spermatogonia. These differences in the germ line organization are very likely due to the differences in reproductive strategies of rodents and primates [Wistuba et al., 2007]. Thus, a non-human primate model sharing the properties of a primate-specific stem cell system is needed [Ehmcke et al., 2006; Dym et al., 2009]. The testicular development, as well as the cellular arrangements within the seminiferous epithelium, of the common marmoset monkey (Callithrix jacchus), is highly similar to that of the human [Weinbauer et al., 2001; Wistuba et al., 2003; Ehmcke et al., 2005; Luetjens et al., 2005; Mitchell et al., 2008; Albert et al., 2010]. In a convergent manner, the Great Apes, including humans, and the New World monkeys, including marmosets, developed a so-called multi-stage seminiferous tubule. These tubules are characterized by the presence of several spermatogenic stages (arrangements that reflect differentiating clusters of cells) within one tubular cross-section, indicating smaller and less synchronized germ cell clones. In contrast, Old World monkeys show a predominantly single-stage organization of their germinal epithelium, which is very likely due to a higher degree of clonal synchronization [Wistuba et al., 2003; Luetjens et al., 2005; Ehmcke et al., 2006].

Another common feature of humans and marmosets is that gonocytes, which later differentiate into spermatogonia, are still present within the seminiferous cords at birth. More precisely, in the neonatal marmoset, the germ cell population consists of about $70 \%$ gonocytes, which are located in the center of the seminiferous tubules, and of $30 \%$ spermatogonia, which have full contact with the basal lamina. Even during the next couple of months of development, gonocytes remain the most prevalent germ cell type [Sharpe et al., 2003a; Albert et al., 2010]. This developmental pattern of a relatively long period of a testis arrested at an immature state also reflects the postnatal human situation. While there are only minor changes with respect to the germ cell types, a morphometric analysis of the marmoset testis has demonstrated a 10 -fold increase in germ cell numbers between birth and 20 weeks of age. Thereafter, a rather quiescent developmental period starts, which lasts until the onset of puberty and initiation of spermatogenesis [Sharpe et al., 2003a]. In a more recent study, Albert et al. [2010] investigated the presence of germ cell types present in the newborn, the 8-week-old and the adult marmoset on the basis of marker expression. It was shown that the proportion of germ cell types was reflected in the expression of the germ cell markers octamer binding protein 3/4 (OCT3/4), DDX4, DEAD (Asp-Glu-Ala-Asp) box polypeptide 4 (VASA) and tyrosine kinase receptor KIT (C-KIT) at the RNA and the protein levels [Albert et al., 2010]. More specifically, within the seminiferous tubules of the newborn testis, OCT3/4 protein expression can be detected in the nucleus of gonocytes. As germ cell differentiation proceeds, the proportion of OCT3/4-positive germ cells decreases [Mitchell et al., 2008; Albert et al., 2010]. The CKIT receptor has been shown to be a marker of later germ cell stages, as it is located on the surface of spermatogonia and its interaction with the ligand stem cell factor is essential for spermatogonial proliferation and differentiation [Loveland and Schlatt, 1997; von Schonfeldt et al., 1999]. Finally, the expression of the RNA-binding protein VASA is detected in the majority of germ cells in the newborn monkey as well as in 8-week-old animals. During later developmental stages, expression increases at the RNA and the protein levels as this marker is expressed in undifferentiated (spermatogonia) as well as differentiated germ cells (spermatids) [Castrillon et al., 2000; Mitchell et al., 2008; Albert et al., 2010].

Apart from the germ cells, the seminiferous tubules contain somatic Sertoli cells, which have distinct functions during development. They are essential for seminiferous cord formation in the fetus and support spermatogenesis at the beginning of puberty. At the molecular level, these changes are activated by the expression of the transcription factor sex determining region Y (SRY) in the male fetus which induces SRY related homeobox pro- 
tein 9 (SOX9) expression and thereby stimulates genes essential for Sertoli cell function [Koopman et al., 2001; Harley et al., 2003]. The proliferation and differentiation of the Sertoli cells finally results in the formation of seminiferous cords enclosing the germ cells [Swain and Lovell-Badge, 1999; Polanco and Koopman, 2007]. The expression of SOX9 also induces the secretion of antimüllerian hormone $(\mathrm{AMH})$, which leads to regression of the müllerian duct [Allard et al., 2000; Viger et al., 2005]. Following a quiescent phase, Sertoli cell proliferation is induced by follicle-stimulating hormone (FSH) at the initiation of puberty, leading to a final number of Sertoli cells that terminally differentiate during puberty. This maturation process is characterized by the downregulation of AMH expression, the formation of tight junctions and the secretion of factors essential for germ cell development. Therefore, mature Sertoli cells are also essential for spermatogenesis, as they provide structural support as well as nourishment [Jegou, 1992; McLaren et al., 1993; Sharpe et al., 2003b].

Peritubular cells (PTCs) are considered to be structural cells, as they surround the basal lamina of the seminiferous tubules containing the germ cells and the somatic Sertoli cells, and have the potential to contract, resulting in the movement of free testicular spermatozoa towards the rete testis [Santiemma et al., 1996; Rossi et al., 2002; Romano et al., 2005]. Developmental studies in rats and rhesus monkeys have demonstrated that the structural protein $\alpha$-smooth muscle actin (SMA) is only expressed after an androgen-dependent differentiation during pubertal development. Therefore, the expression of this protein appears to reflect the different stages of PTC differentiation and may indicate distinct functions during development [Tung and Fritz, 1990; Schlatt et al., 1993]. This assumption is supported by recent studies on the secretome of human PTC cultures. In the frame of these studies, a number of growth factors and cytokines have been identified, indicating that PTCs may form part of the spermatogonial stem cell niche and may therefore play a role during testicular development as well as for spermatogenesis [Albrecht et al., 2006; Mackay and Smith, 2007; Schell et al., 2008; Spinnler et al., 2010].

In the marmoset monkey, a 5 -fold increase in testicular weight occurs between birth and 20 weeks of age. This increase is caused by the proliferation of testicular Sertoli cells and PTCs and a 10-fold increase in germ cell numbers [Sharpe et al., 2003a]. To understand the cellular dynamics and features that contribute to this developmental phase of the testis better, separate analyses of isolated pure fractions of the various cell types are a prerequisite. How- ever, despite the fact that the marmoset monkey is considered a valuable model for humans with regard to its testicular development and the organization of the seminiferous epithelium, meaningful markers for testicular somatic cells are largely unknown. Therefore, the first aim of this study was to identify markers that facilitate the detection of Sertoli cells and PTCs in the marmoset testis at different developmental time points. Another aim was to establish monolayer cultures of testicular cells and to characterize these cultures by employing quantitative PCR (qPCR) and immunohistochemistry.

\section{Materials and Methods}

\section{Animals and Tissue Collection}

Marmoset monkeys were derived from the institutional breeding facilities. They were deeply anesthetized with $1 \mathrm{ml}$ Ketaject (Parke-Davis, Munich, Germany; equivalent to $100 \mathrm{mg} / \mathrm{ml}$ ketamine per animal) and sacrificed by decapitation, in accordance with the German Federal Law on the Care and Use of Laboratory Animals (license No. A 924/2007; 8.87-50.10.46.09.018). Testes were removed, weighed and their volume estimated from caliper measurements. In total, testicular tissue from 4 newborn, seven 8 -week-old and 4 adult marmoset monkeys was used in this study.

\section{Testicular Tissue Processing for Histology and}

Immunohistochemistry

Testicular tissue from newborn $(\mathrm{n}=1), 8$-week-old $(\mathrm{n}=1)$ and adult marmoset monkeys $(\mathrm{n}=2)$ was used for immunohistochemical analyses. A small tissue sample from each testis was fixed overnight at room temperature in Bouin's fixative and was then washed and stored in $70 \%(\mathrm{v} / \mathrm{v})$ ethanol. Subsequently, tissues were routinely embedded in paraffin and sectioned at $5 \mu \mathrm{m}$ with a Leica SM2000R microtome (Leica Microsystems GmbH, Wetzlar, Germany).

\section{Immunohistochemistry on Tissue Sections}

Paraffin sections were dewaxed in solvent (ProTaqs Clear, Cat. No. 4003011; Quartett Immunodiagnostika and Biotechnologie, Berlin, Germany), rehydrated in a decreasing ethanol series, washed in tap water for $20 \mathrm{~min}$ and with distilled water for $5 \mathrm{~min}$. For antigen retrieval, sections were heated in citrate buffer $(\mathrm{pH} 6)$ in a microwave oven to approximately $85^{\circ} \mathrm{C}$. After cooling to room temperature, sections were washed in Tris-buffered saline (TBS), and non-specific peroxidases were blocked with $3 \%(\mathrm{v} / \mathrm{v})$ $\mathrm{H}_{2} \mathrm{O}_{2}$ for $15 \mathrm{~min}$ at room temperature. After being washed with distilled water and TBS, unspecific antibody binding was blocked for $30 \mathrm{~min}$ with $25 \%(\mathrm{v} / \mathrm{v})$ chicken or goat serum in TBS containing $0.5 \%(\mathrm{w} / \mathrm{v}) \mathrm{BSA}$, in a humid chamber at room temperature. Sections were then incubated with the primary antibody overnight in a humid chamber at $4^{\circ} \mathrm{C}$. Primary antibodies used were anti-AMH (dilution 1:100, goat polyclonal, Santa Cruz sc-6886), anti-vimentin (anti-VIM, dilution 1:50, rabbit polyclonal, Santa Cruz sc-5565), and anti-SMA (dilution 1:1,000, mouse monoclonal, Sigma A2547). Sections were then washed with TBS, incubated with the corresponding (anti-goat, anti-rabbit or anti- 
Table 1. Marmoset-specific primer sequences used for qPCR analyses

\begin{tabular}{|c|c|}
\hline Gene name & Primer sequences \\
\hline$A M H$ & $\begin{array}{l}\text { Forward: 5'-GGGCTCTGCTAGGGACTGAGA-3' } \\
\text { Reverse: 5'-GGCCAGTCCACCTCTTCAAAGAT-3' }\end{array}$ \\
\hline FSHR & $\begin{array}{l}\text { Forward: 5'-GAAAGTGTGACTCTATGGCTGAATAAGA-3' } \\
\text { Reverse: 5'-CTCATCTAGTTGGGTTCCATTGAA-3' }\end{array}$ \\
\hline SOX9 & $\begin{array}{l}\text { Forward:5'-TGGGCAAGCTCTGGAGATTT-3' } \\
\text { Reverse: 5'-TCCGCCTCCTCCACGAA-3' }\end{array}$ \\
\hline VIM & $\begin{array}{l}\text { Forward: 5'-TCCCTGAACCTGAGGGAAACT-3' } \\
\text { Reverse: 5'-CGTCTTAATCAGAAGTGTCCTTTTTG-3' }\end{array}$ \\
\hline$S M A$ & $\begin{array}{l}\text { Forward: 5'-CGTGAGAAGATGACGCAGATCA-3' } \\
\text { Reverse: 5'-CAGCCTGGATGGCCACAT-3' }\end{array}$ \\
\hline
\end{tabular}

mouse IgG) horseradish peroxidase-conjugated secondary antibody solution (dilution 1:100) for $1 \mathrm{~h}$ at room temperature, and were again washed with TBS. Then sections were treated with diaminobenzidine solution (Cat. No. D4168; Sigma-Aldrich) in a humid chamber for up to $20 \mathrm{~min}$, rinsed with distilled water and counterstained with hematoxylin. Finally, sections were washed in tap water for $5 \mathrm{~min}$, rinsed with distilled water, dehydrated and mounted using a xylene-based permanent mounting medium (Merckoglas, Cat. No. 1.03973.0001; Merck, Darmstadt, Germany). Images were captured with an Olympus BX-61 microscope (Olympus, Melville, N.Y., USA) with a QImaging Retiga 4000R camera and were analyzed with QCapture 2.73 (Quantitative Imaging Corporation 2005, Burnaby, B.C., Canada).

\section{Quantitative Real-Time PCR Analysis}

Using testicular tissue from newborn $(\mathrm{n}=4), 8$-week-old ( $\mathrm{n}=$ 4 ) and adult marmoset monkeys $(n=4)$, marmoset-specific marker genes that have been shown to be informative of distinct germ cell stages or testicular somatic cells, were chosen for mRNA analysis. OCT3/4 was used as a marker for gonocytes, C-KIT as marker for differentiating spermatogonia and VASA as a general germ cell marker. To assess the presence of somatic cells, marmosetspecific primers for the Sertoli cell marker genes SOX9, AMH, FSH receptor (FSHR) and VIM were established for this study. Finally, primers for SMA, which is expressed by PTCs, were designed.

Gene sequences were chosen on the basis of the Trace Archive of the National Center for Biotechnology Information. Subsequently, marmoset-specific primers were designed, if possible crossing exon boundaries, by employing PrimerExpress ${ }^{\circledR}$. Corresponding primer sequences of the somatic marker genes are listed in table 1. Optimal primer concentrations and product specificity were assessed by following the guidelines of Applied Biosystems for SYBR ${ }^{\circledR}$ Green-based PCR analysis, as was outlined in detail in our previous publication [Albert et al., 2010]. Each sample was assayed in duplicate and was normalized to glyceraldehyde-3-phosphate dehydrogenase.

\section{Isolation of Testicular Cells}

To determine the optimal protocol for the enzymatic dissociation of testes from 8-week-old marmoset monkeys $(n=3)$, testes were decapsulated and treated according to the following protocols (fig. 1). One testis from each monkey was dissociated by a single digestion step (digestion I). Tissue was incubated with collagenase IV $(1 \mathrm{mg} / \mathrm{ml})$ for $20 \mathrm{~min}$ at $37^{\circ} \mathrm{C}$. Following this digestion, the cells were left to settle at unit gravity at room temperature for $15 \mathrm{~min}$ to achieve the separation of the seminiferous tubules from the interstitial cells. Cells present in the supernatant I (SN I) and in the pellet I (PL I) were collected separately and plated onto $0.1 \%(\mathrm{w} / \mathrm{v})$ gelatin-coated 24 -well plates and were then incubated at $37^{\circ} \mathrm{C}$ and $5 \%$ (v/v) $\mathrm{CO}_{2}$ (fig. 1a). For the second testis, the cells and the seminiferous tubules present in PL I after sedimentation were further digested with trypsin-EDTA $0.05 \%(\mathrm{w} / \mathrm{v})$ and DNase I $(7 \mathrm{mg} / \mathrm{ml})$ for $5 \mathrm{~min}$ at $37^{\circ} \mathrm{C}$. The reaction was stopped by addition of culture medium and the cells were collected by centrifugation for $5 \mathrm{~min}$ at $200 \mathrm{~g}$. The supernatant was discarded and PL II was resuspended and plated onto gelatincoated plates, by using the culture conditions outlined above (fig. 1b). For expression analysis, an aliquot was collected from each of the three samples (SN I, PL I, PL II), cell numbers were adjusted to approximately 300,000 cells $/ \mathrm{ml}$ and cells were snapfrozen in liquid nitrogen. Remaining cells were used to establish short-term cultures.

\section{Culture Conditions for Testicular Cells}

For short-term culture of testicular cells, two culture media were compared. For condition I, the cells were cultured in germ cell culture medium consisting of DMEM high glucose (Invitrogen GmbH, Darmstadt, Germany), 1\% (v/v) FCS, 1\% (w/v) penicillin/streptomycin, MEM non-essential amino acids (Invitrogen), 5 $\times 10^{-5} \mathrm{M} \beta$-mercaptoethanol and $20 \mathrm{ng} / \mathrm{ml}$ human recombinant glial cell-derived neurotrophic factor (R\&D Systems, Abingdon, UK). For condition II, cells were cultured in marmoset embryonic stem cell medium containing knockout DMEM (Invitrogen), 10\% $(\mathrm{v} / \mathrm{v})$ knockout serum replacement, $1 \%(\mathrm{w} / \mathrm{v})$ penicillin/streptomycin, MEM non-essential amino acids (Invitrogen), $5 \times 10^{-5} \mathrm{M} \beta$ mercaptoethanol and $20 \mathrm{ng} / \mathrm{ml}$ human recombinant glial cell-derived neurotrophic factor. The medium was changed every 4 days and cells were passaged by trypsinization [trypsin $0.05 \%(\mathrm{w} / \mathrm{v})-$ EDTA]. Following this digestion, cells were harvested by centrifugation at $200 \mathrm{~g}$ for $5 \mathrm{~min}$, washed with PBS and replated in the respective medium. In addition, one of these cultures was maintained in germ cell medium for 7 months and is referred to as longterm testicular cell culture throughout this work.

\section{Immunofluorescence Staining}

Cells were rinsed with PBS and fixed in $4 \%(\mathrm{w} / \mathrm{v})$ paraformaldehyde in PBS for $15 \mathrm{~min}$ at room temperature. After three 5-min washes in PBS containing $100 \mathrm{~mm}$ glycine, the cells were permeabilized with $0.1 \%(\mathrm{v} / \mathrm{v})$ Triton X-100 for $4 \mathrm{~min}$. Cells were blocked with $10 \%(\mathrm{w} / \mathrm{v})$ BSA in PBS and were incubated at room temperature for $30 \mathrm{~min}$. Primary antibody dilutions were 1:100 for VIM (Cat. No. sc-5565; Santa Cruz Biotecnology, Inc., Heidelberg, Germany) and 1:500 for SMA (Cat. No. A2547; Sigma-Aldrich, Steinheim, Germany) diluted in $2 \%(\mathrm{v} / \mathrm{v})$ goat serum in PBS. For double staining, cells were incubated with primary antibodies against VIM and SMA for $1 \mathrm{~h}$ at room temperature. After incubation with the primary antibodies, slides were washed three times for $5 \mathrm{~min}$ in PBS containing $100 \mathrm{mM}$ glycine. Cells were then incubated with corresponding secondary antibodies at a dilution of 1:100 at room temperature for $1 \mathrm{~h}$. Whereas goat anti-mouse Alexa 488 (Cat. No. 


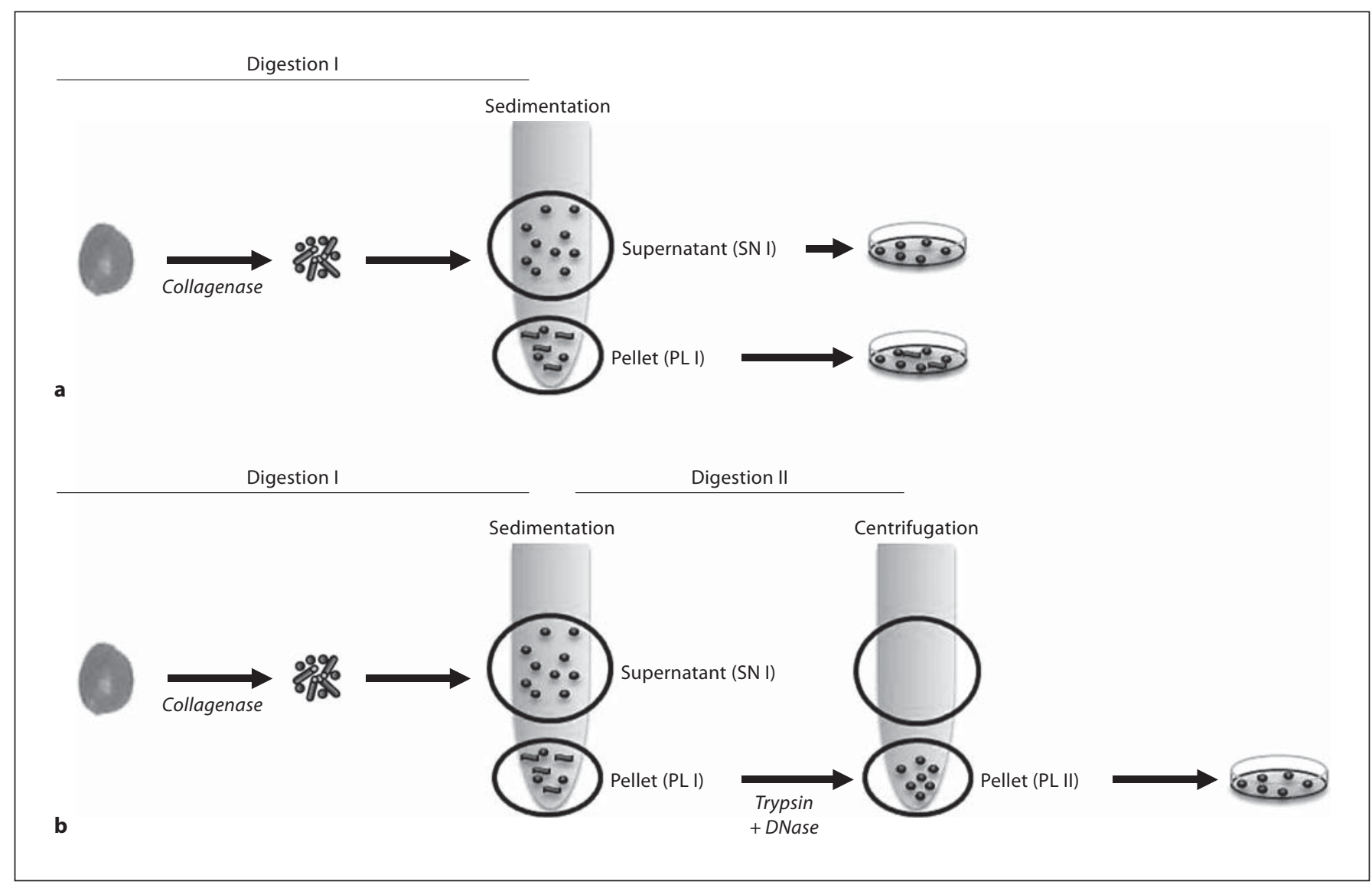

Fig. 1. Schematic outline of the testicular digestion protocol. a Following the one-step digestion and subsequent sedimentation at unit gravity, cells from the supernatant (SN I) and from the pellet (PL I) were collected. 300,000 cells were frozen for RNA isola- tion, whereas the remaining cells were plated onto gelatin-coated dishes. b After two-step enzymatic digestion, the cells were collected by centrifugation and were either used for RNA isolation or plated as outlined above.
A11001; Invitrogen) was used for detection of SMA, goat antirabbit Alexa 546 (Cat. No. A11035; Invitrogen) was used for detection of VIM. DAPI was used as nuclear counterstain and cells were subsequently mounted with Vectashield (Cat. No. H-1200; Vector Laboratories, Inc., Burlingame, Calif., USA). Analysis and image acquisition were performed as stated above.

\section{Results}

Immunohistochemical Analysis of Sertoli and

PTC-Specific Markers in the Newborn, the

8-Week-Old and the Adult Marmoset Testis

The cytoplasm of Sertoli cells was clearly immunopositive for AMH in testicular sections from the newborn and the 8-week-old but not from the adult marmoset (fig. 2a-c). However, VIM was expressed by Sertoli cells at all three developmental time points (fig. $2 \mathrm{~d}-\mathrm{f}$ ). While expression of SMA was only detected in blood vessels in the newborn marmoset testis, a strong staining was found in the PTCs as well as in the blood vessels in the 8-weekold and the adult marmosets (fig. $2 \mathrm{~g}-\mathrm{l}$ ).

\section{Relative Expression of Germ Cell- and Somatic}

Cell-Specific Marker Genes in the Testicular Tissue of the Marmoset at Different Developmental Stages qPCR analyses of somatic marker genes revealed an increased expression of SOX9 (7-fold), AMH (4.5-fold), FSHR (16-fold) and SMA (4-fold) in the 8-week-old marmoset testis over that of the newborn. Slightly lower expression of these somatic marker genes was observed in the adult marmoset testis compared to the 8-week old (fig. 3a).

In addition, relative expression of germ cell-specific marker genes was analyzed. We found that the expression of the pluripotency marker OCT3/4 was 12 times lower in 

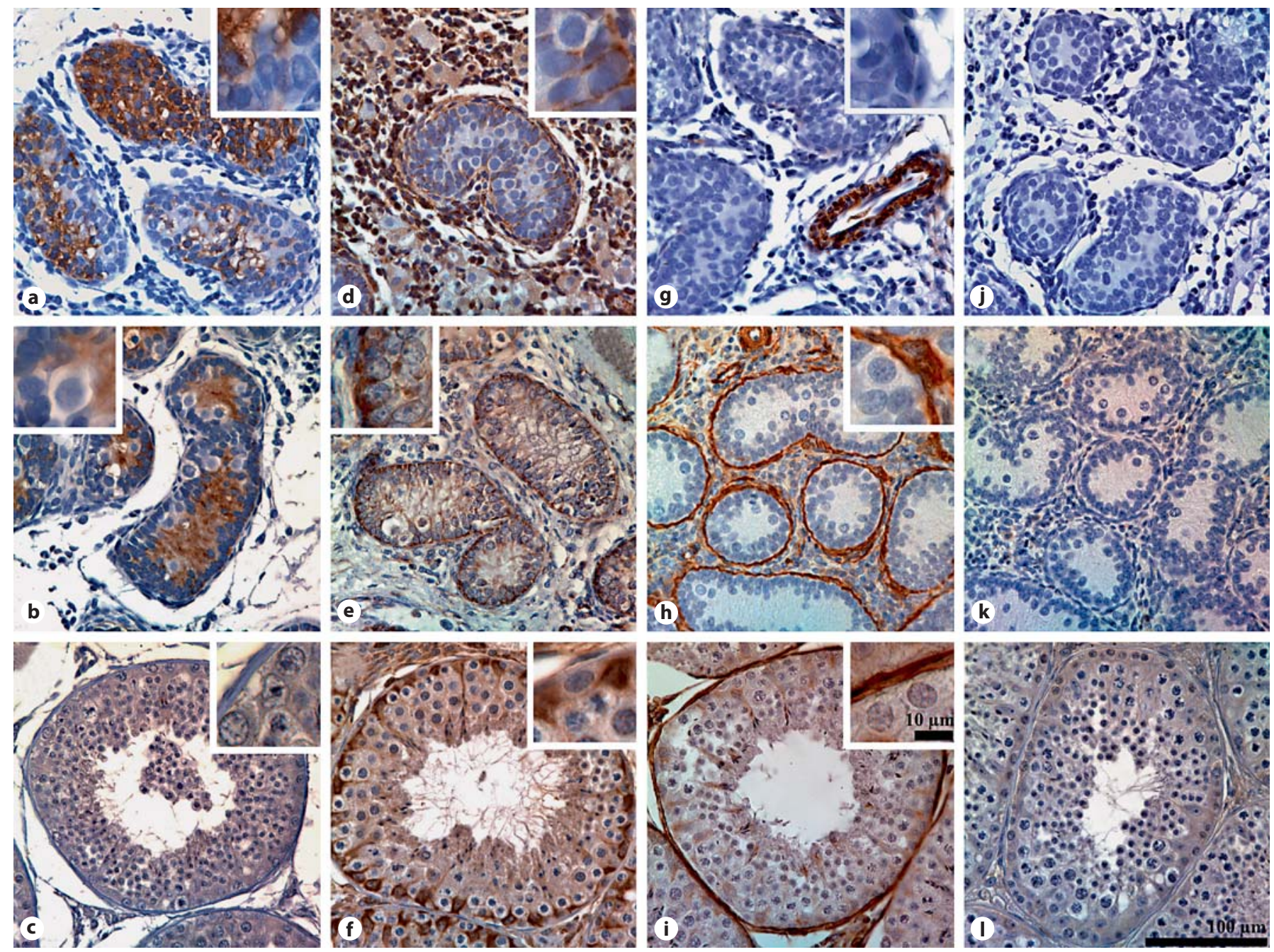

Fig. 2. Micrographs showing the immunohistochemical staining of testicular somatic markers. Detection of AMH (a-c), VIM (df) and SMA ( $\mathbf{g}-\mathbf{i})$ in the newborn $(\mathbf{a}, \mathbf{d}, \mathbf{g}, \mathbf{j})$, the 8-week-old (b, e, $\mathbf{h}, \mathbf{k})$ and the adult marmoset monkey $(\mathbf{c}, \mathbf{f}, \mathbf{i}, \mathbf{I})$ is shown. Incuba-

tion with corresponding IgG antibodies was used as negative control (j-I). Scale bars represent 10 and $100 \mu \mathrm{m}$ and are representative for all respective micrographs.

the 8-week-old and the adult marmoset monkey than in the newborn. In contrast, the expression of the differentiating germ cell marker genes VASA and C-KIT was found to be similar in the testis of the newborn and the 8 -week-old marmoset testis but was increased in the testicular tissue of adult animals, by 20 - and 3-fold, respectively (fig. 3b).

To assess the proportion of the different cell types in the testicular tissue obtained from the 8-week-old marmoset, the relative expression of germ cell- and somatic cell-specific marker genes was compared. These analyses revealed that OCT3/4 expression was low compared with that of VASA (9-fold) and C-KIT (5-fold). Even more pro-

nounced differences were detected in the expression of the somatic genes SOX9, FSHR, VIM and SMA, which were approximately 350 -fold increased over that of OCT3/4 and 50 -fold increased over that of the markers of differentiated germ cells VASA and C-KIT. The expression of AMH was even 12.400-, 1.400- and 2.600-fold higher than that of OCT3/4, VASA and C-KIT, respectively (fig. 3).

\section{Expression Analysis following Enzymatic Digestion of}

Testicular Tissue from the 8-Week-Old Marmoset

Following the first and the second enzymatic digestion, RNA expression profiles were monitored by qPCR to identify the proportion of germ cells and somatic cells 


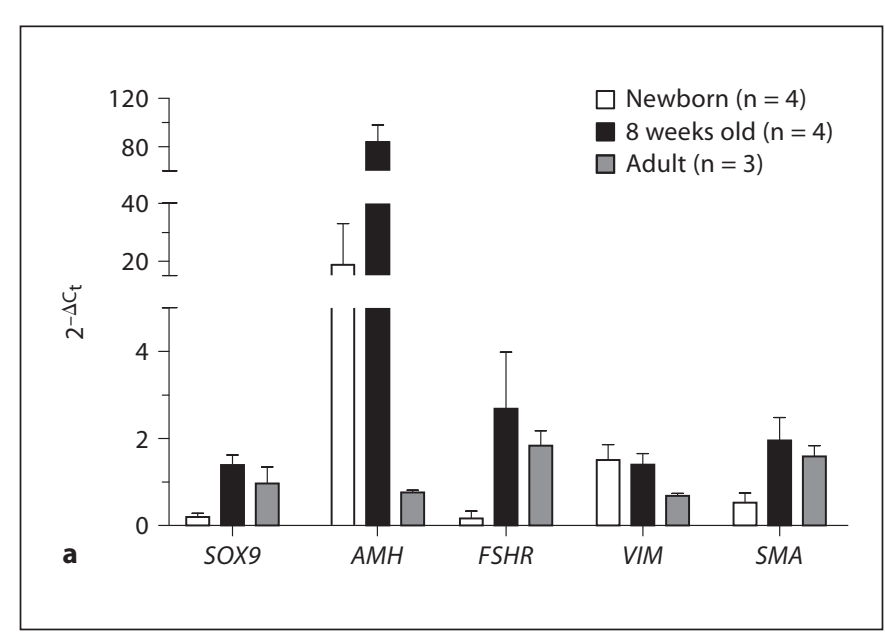

Fig. 3. qPCR results for germ cell- and somatic cell-specific marker genes. Data shown are presented as $2^{-\Delta C_{t}}$ values according to Schmittgen et al. [Livak and Schmittgen, 2001, 2008] and results are shown as the mean \pm SEM. a Expression of Sertoli cell(SOX9, AMH, FSHR and VIM) and PTC-specific marker genes

in the different fractions (experimental outline in fig. 1). These analyses revealed that the supernatant (SN I) contained cells expressing early and late germ cell marker genes, as well as cells positive for the somatic genes VIM and SMA (fig. 4). Furthermore, with the exception of OCT3/4, neither the pellet collected after the first (PL I) nor after the second enzymatic digestion (PL II) was enriched for cells expressing germ cell- or even somatic cellspecific marker genes. Rather, a general decrease in expression was observed in those fractions collected after the first and second enzymatic digestion compared with those from the supernatant.

\section{Short-Term Culture of Testicular Cells from the 8-Week-Old Marmoset}

For short-term culture experiments, germ cell medium and marmoset embryonic stem cell medium were compared. In both media, cells from the SN I, PL I and PL II grew as a monolayer of heterogeneous cell types (fig. 5a). After 7 days of culture, cells were collected for qPCR analysis and representative results of the cells obtained from PL II are shown as example in figure 5b. Irrespective of the fraction analyzed and the medium used, the expression of germ cell-specific marker genes OCT3/4, VASA and C-KIT was hardly detectable after 7 days of culture. Furthermore, while the expression of the Sertoli cell-specific marker genes SOX9, AHM and FSHR was generally higher in cells grown in germ cell medium than

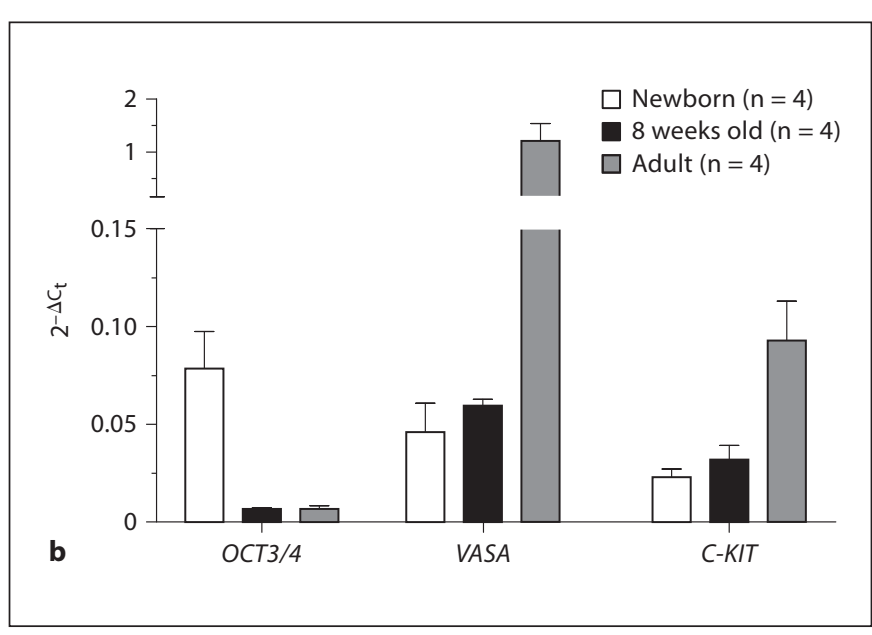

(SMA) in newborn, 8-week-old and adult marmoset monkeys. b qPCR analysis for the gonocyte marker gene (OCT3/4) and differentiating germ cell marker genes (C-KIT and VASA) in the newborn, the 8-week-old and the adult marmoset testis.

in those grown in embryonic stem cell medium, levels were still reduced 3-, 125- and 13-fold, respectively, following 7 days of culture. In contrast to the decreasing levels of the germ cell- and Sertoli cell-specific marker genes, the expression of the somatic markers VIM and $S M A$ remained constant over 7 days of culture.

\section{Long-Term Cultures and Gene Expression of \\ Testicular Cells}

To monitor the composition of testicular cell types during long-term cultures, cells were collected monthly for qPCR analysis of specific marker genes. While the cell population showed no expression of the germ cell marker genes OCT3/4, VASA and C-KIT, the expression of the Sertoli cell marker genes SOX9 and $A M H$ was detected after 1 month of culture but not at subsequent time points. In contrast, VIM and SMA expression was detected throughout the entire culture period (fig. 6a).

Furthermore, immunofluorescence analyses revealed that the majority of cells solely expressed SMA. However, a few cells could be detected that only expressed VIM or were positive for both markers (fig. 6b). In agreement with the qPCR data, no expression of the germ cell markers OCT3/4, VASA and C-KIT was detected (data not shown). 


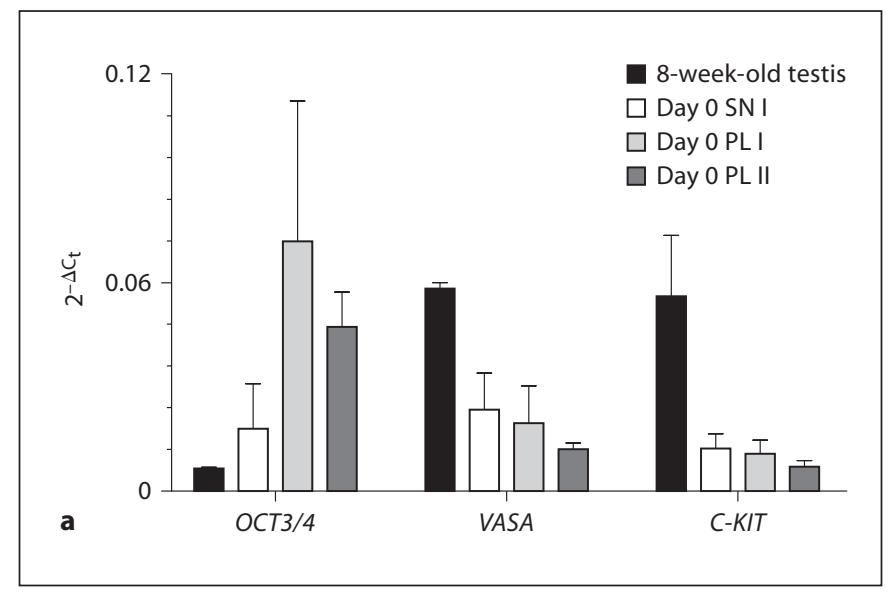

Fig. 4. Relative RNA expression following the enzymatic digestion of 8-week-old marmoset testes $(n=3)$. Results are shown as $2^{-\Delta C_{t}}$ values according to Schmittgen and Livak $[2001,2008]$ and are presented as the mean \pm SEM. a RNA was obtained from the collagenase-digested supernatant fraction (SN I), the collagenase-

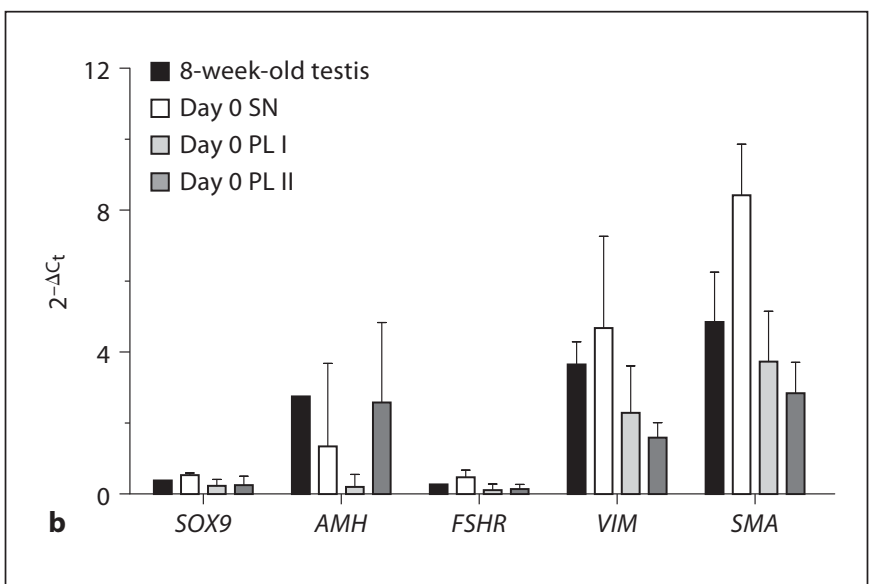

digested pellet fraction (PL I) and the collagenase-trypsinDNase-digested pellet fraction (PL II), using RNA from the 8 -week-old marmoset testis as control. qPCR analyses were performed for the germ cell-specific marker genes (a) as well as for the Sertoli cell and PTC marker genes (b).
Fig. 5. Phase contrast micrographic images and qPCR results of testicular cells following short-term culture. a Testicular cells after 7 days of culture in germ cell medium with $1 \%$ FCS. Scale bar $=50 \mu \mathrm{m}$. b Representative qPCR data obtained following 7 days of culture of testicular cells from cell pellet PL II. Relative expression of the germ cell- and somatic cell-specific marker genes of cells cultured in germ cell medium (GC med) and embryonic stem cell medium (ESC med) was determined, using day 0 of culture as control. Data are shown as $2^{-\Delta \mathrm{C}_{t}}$ values according to Schmittgen and Livak [2001, 2008] and are presented as the mean \pm SEM.

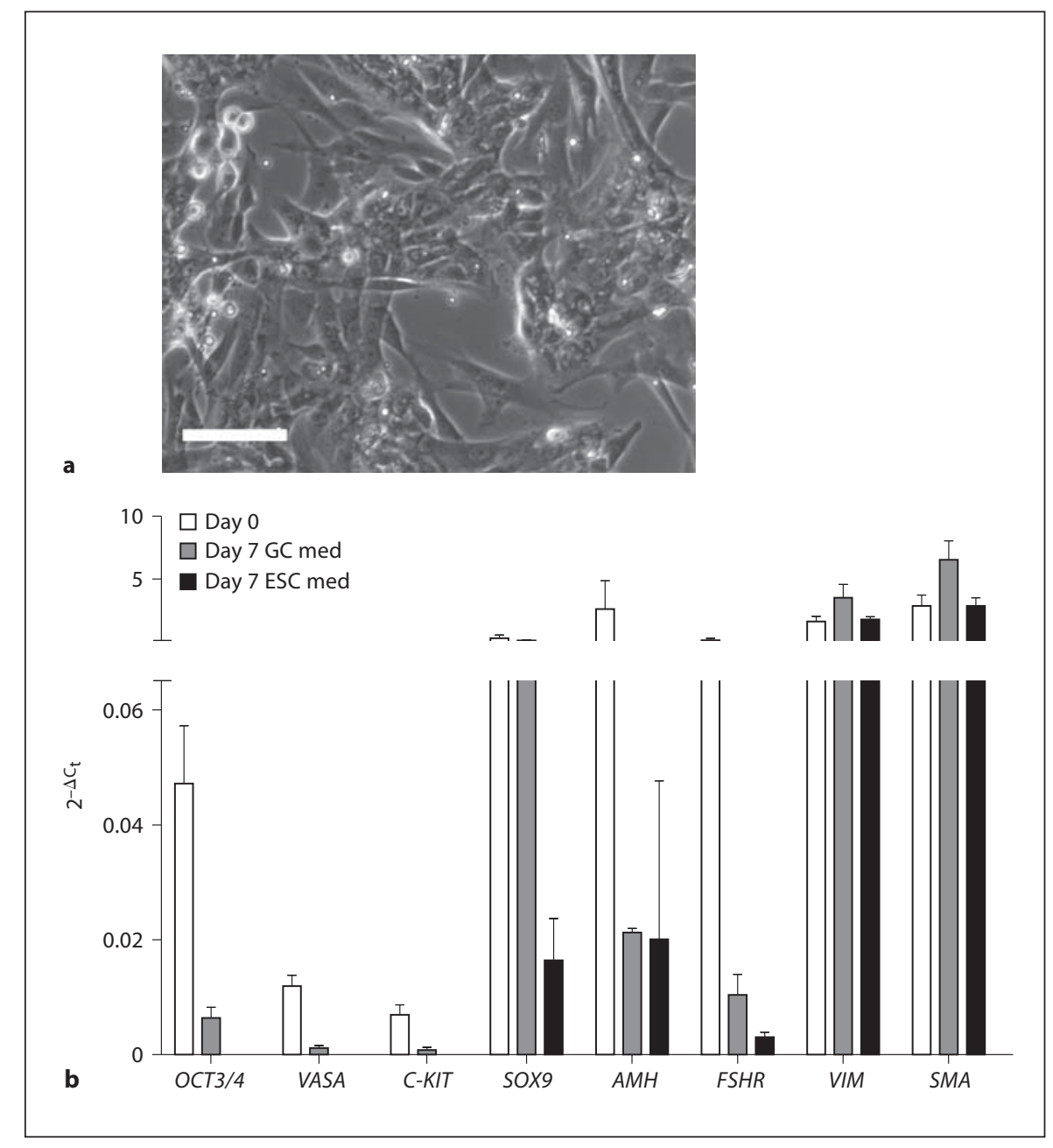


Fig. 6. Expression analysis during longterm culture experiments. a Expression analysis of germ cell- and somatic cell-specific marker genes during long-term testicular cell culture from an 8-week-old marmoset $(n=1)$. qPCR analyses were performed each month, over a period of 7 months. Results are shown as $2^{-\Delta C_{t}}$ values according to Schmittgen and Livak [2008] and are presented as the mean \pm SEM. b Immunofluorescence analysis performed after 5 months of testicular cell culture in germ cell medium. Costaining for VIM (red cytoplasmic staining), SMA (green cytoplasmic staining) and DAPI (blue nuclear staining) resulted in cells only positive for SMA (asterisks), cells only positive for VIM (arrow), cells positive for both markers (arrowhead) and cells negative for both markers (hash). Scale bar = $50 \mu \mathrm{m}$.
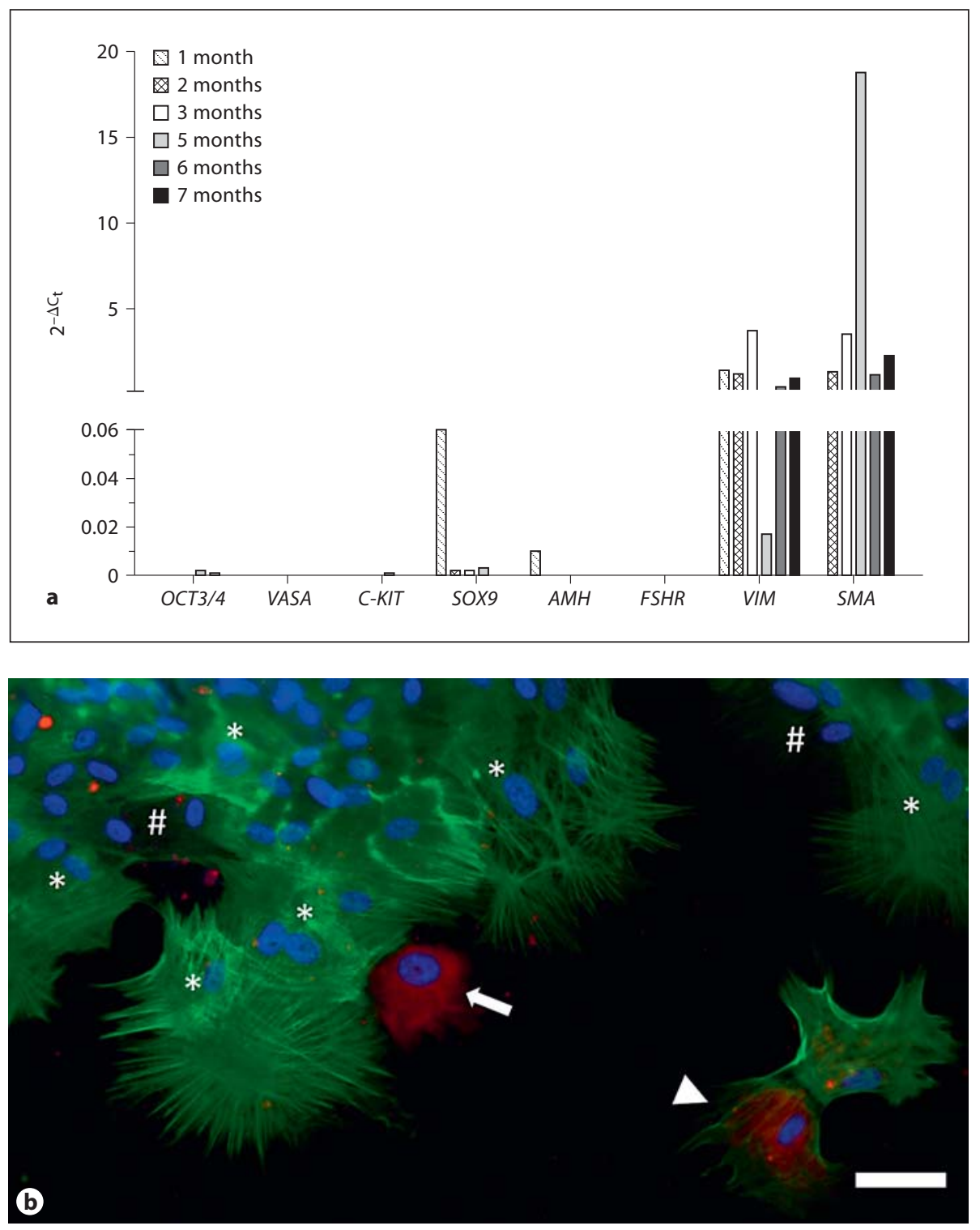

\section{Discussion}

In this study, we chose to use the marmoset monkey, which is widely used as a non-human primate model in reproductive medicine, for the establishment of testicular cell cultures. At the age of 8 weeks, the testicular tissue of these primates shows a beneficial germ cell to somatic cell ratio and a high proliferative potential of somatic peritubular and Sertoli cells. For this reason, we decided to use marmoset testes of this age to find optimal conditions to expand pure populations of testicular germ and somatic cells. For a detailed analysis of testis-derived cell cultures, markers facilitating the characterization of the respective cell populations had to be selected. As a germ cell-specific marker panel had been established in a previous study [Albert et al., 2010], the focus of this study was to evaluate the expression levels of Sertoli (SOX9, AMH, FSHR, and VIM) and peritubular (SMA) cell-specific markers at the RNA and the protein levels at different developmental time points.

The transcription factor SOX9 is involved in the regulation of the secreted glycoprotein $\mathrm{AMH}$, which plays a role in the remodeling of the male reproductive tract [Morais da Silva et al., 1996; De Santa Barbara et al., 1998]. Interestingly, our immunohistochemical analysis revealed that the immunoexpression of $\mathrm{AMH}$, which is 
expressed in the Sertoli cells of the newborn and the 8 -week-old, but not in the adult marmoset, parallels the changing AMH levels observed in humans [Aksglaede et al., 2010]. The same is true for the intermediate filament marker VIM, which is expressed in the Sertoli cells of the fetal as well as the adult human testis [Rogatsch et al., 1996]. In our study, we could demonstrate that VIM shows the same expression in the marmoset, where it can be detected in the Sertoli cells of the newborn, the 8-weekolds as well as the adult.

As a PTC marker, we investigated the expression of SMA, which is a component of the cytoskeleton, and found that the expression of this structural protein appears to be dependent on the differentiation status of the PTCs. While only the vascular cells were immunopositive for SMA in the newborn monkey, a distinct expression was detected in the PTCs of the 8-week-old and the adult marmoset. These results are in line with previous studies in the rhesus monkey and the rat, which have demonstrated that SMA is a marker for the differentiation status of PTCs [Tung and Fritz, 1990; Schlatt et al., 1993].

Furthermore, we could demonstrate that the RNA expression of SOX9, AMH, FSHR, VIM and SMA in the newborn, the 8-week-old and the adult marmoset reflects the increase in somatic cell numbers during early developmental stages, as well as the declining proportion of mRNA contributed by somatic cells following the establishment of spermatogenesis in the adult. In addition, the expression of AMH accords with the differentiation status of the Sertoli cells at the three time points investigated. The FSHR has previously been shown to be expressed in fetal, newborn and adult human Sertoli cells, as found by RNA expression data in the marmoset [Bockers et al., 1994; Plant and Marshall, 2001; Boukari et al., 2009]. Importantly, for the Sertoli cell marker genes $A M H$ and VIM and the peritubular marker gene SMA, the expression detected by qPCR analysis was consistent with the immunohistochemical data. The same was true for the germ cell marker genes investigated in this study. We found that OCT3/4 expression reflected the decreasing proportion of undifferentiated germ cells in the 8-weekold and the adult marmoset testis compared with that of the newborn. Furthermore, the increased expression of VASA and C-KIT reflected the cellular composition of the testicular tissue, as the differentiating germ cell types account for the larger part of the total cell population in the adult testis compared with that of the rather immature stages in the newborn and the 8-week-old marmoset testis. These findings are in accordance with previous stud- ies on the number of OCT3/4- and VASA-immunopositive cells during development of the marmoset monkey. More specifically, those studies have demonstrated that while the total number of OCT3/4-immunopositive cells in the newborn and the 8-week-old marmoset remains stable, these undifferentiated cells constitute a smaller proportion of the total testicular cell population, whereas the proportion of differentiated germ cells expressing VASA increases [Albert et al., 2010].

As testicular tissue of 8-week-old marmoset monkeys contains few germ cells with stem cell properties relative to the number of somatic Sertoli and PTCs, we investigated whether approaches to enrich germ cells from murine testes could be transferred to the marmoset. By performing a two-step enzymatic digestion of testes obtained from adult mice, it was reported that the supernatant fraction contained mostly interstitial cells following the first digestion, whereas the cell pellet was enriched in germ cells, somatic Sertoli and PTCs [von Schonfeldt et al., 1999]. The same approach was also successfully used by Stukenborg et al. [2008], despite the fact that testes were obtained from 10-day-old mice and were minced before the enzymatic digestion [Stukenborg et al., 2008]. However, the results which were obtained in this study demonstrated that the seminiferous cords from the 8-week-old marmoset released part of the germ cell fraction during the first step of the enzymatic digestion, resulting in the presence of cells expressing OCT3/4, VASA and C-KIT in the supernatant. One reason for these findings could be the immature and rather disorganized status of the marmoset testicular cords. Therefore, the separation of the supernatant fraction following the first step of the enzymatic digestion may not allow enrichment of the germ cell fraction, emphasizing the differences between rodents and primates and the need for marmoset-specific protocols.

The evaluation of the testicular short-term cultures from the immature marmoset monkeys showed that PTCs constituted the dominant cell type after 7 days of culture, whereas the proportion of Sertoli cells and germ cells decreased, irrespective of the cell fraction and the medium used. Performing qPCR analyses to analyze long-term cultures, we found that Sertoli cell-specific marker genes could only be detected after 1 month of culture but not at subsequent time points, whereas VIM and SMA levels remained constant over the entire culture period. In agreement with these results, immunofluorescence analysis revealed that cultures mostly consisted of SMA-positive PTCs. However, individual cells expressing either only VIM or both markers could also be detected. Therefore, our data suggest that the culture pri- 
marily consisted of PTCs and few Sertoli cells. The low expression levels of the Sertoli cell marker genes SOX9 and $A M H$ could be due to the low Sertoli cell numbers. However, a reduced marker gene expression has previously been observed in somatic cells isolated from human fetal testicular tissue, indicating that Sertoli cells may change their expression under long-term culture conditions [Cowan et al., 2010].

In this study, we demonstrated that the expression of functionally meaningful markers for testicular development, including AMH and SMA, is in agreement with the marker expression in human testicular tissue. Therefore, the marmoset monkey can indeed be used as a model for human testicular development. Furthermore, our data stress the need for marmoset-specific protocols for the dissociation of testicular tissue, as well as for subsequent germ cell and Sertoli cell culture conditions. However, irrespective of the conditions used, the PTCs were the dominant cell type, which maintained their proliferative potential. The function of PTCs in testicular development and in male infertility has remained largely unsettled, owing to the lack of appropriate culture systems for human PTCs. Only in recent years have in vitro culture systems for human adult PTCs been established, which led to the identification of growth factors and cytokines that are secreted by this cell type [Schell et al., 2008; Albert et al., 2010]. Therefore, the establishment of PTC cultures from the marmoset monkey would facilitate the detailed analysis of the secretome at different developmental periods and would provide the opportunity to analyze general primate features. Such studies would enable the identification of factors involved in the regulation of somatic cell proliferation during early development and the initiation of spermatogenesis.

\section{Acknowledgments}

This study was supported by the German Research Foundation by an unrestricted grant within the Research Unit 'Germ Cell Potential' (FOR 1041-GR 1547/11-1) and by BMBF grant 01GN 0809/0810 entitled 'Pluripotent cells in primate testes'.

We thank Nicole Terwort and Jutta Salzig for their technical assistance and Martin Heuermann and Günter Stelke for animal care, as well as Trevor G. Cooper for the English language editing.

\section{References}

Aksglaede, L., K. Sorensen, M. Boas, A. Mouritsen, C.P. Hagen, R.B. Jensen, J.H. Petersen, A. Linneberg, A.M. Andersson, K.M. Main, N.E. Skakkebaek, A. Juul (2010) Changes in anti-Mullerian hormone (AMH) throughout the life span: a population-based study of 1027 healthy males from birth (cord blood) to the age of 69 years. J Clin Endocrinol Metab 95: 5357-5364.

Albert, S., J. Ehmcke, J. Wistuba, K. Eildermann, R. Behr, S. Schlatt, J. Gromoll (2010) Germ cell dynamics in the testis of the postnatal common marmoset monkey (Callithrix jacchus). Reproduction 140: 733-742.

-Albrecht, M., R. Ramsch, F.M. Kohn, J.U. Schwarzer, A. Mayerhofer (2006) Isolation and cultivation of human testicular peritubular cells: a new model for the investigation of fibrotic processes in the human testis and male infertility. J Clin Endocrinol Metab 91: 1956-1960.

-Allard, S., P. Adin, L. Gouedard, N. di Clemente, N. Josso, M.C. Orgebin-Crist, J.Y. Picard, F. Xavier (2000) Molecular mechanisms of hormone-mediated Mullerian duct regression: involvement of beta-catenin. Development 127: 3349-3360.
-Bockers, T.M., E. Nieschlag, M.R. Kreutz, M. Bergmann (1994) Localization of folliclestimulating hormone (FSH) immunoreactivity and hormone receptor mRNA in testicular tissue of infertile men. Cell Tissue Res 278: 595-600.

Boukari, K., G. Meduri, S. Brailly-Tabard, J. Guibourdenche, M.L. Ciampi, N. Massin, L. Martinerie, J.Y. Picard, R. Rey, M. Lombes, J. Young (2009) Lack of androgen receptor expression in Sertoli cells accounts for the absence of anti-Mullerian hormone repression during early human testis development. J Clin Endocrinol Metab 94: 1818-1825.

Castrillon, D.H., B.J. Quade, T.Y. Wang, C. Quigley, C.P. Crum (2000) The human VASA gene is specifically expressed in the germ cell lineage. Proc Natl Acad Sci USA 97: 9585-9590.

Cowan, G., A.J. Childs, R.A. Anderson, P.T. Saunders (2010) Establishment of long-term monolayer cultures of somatic cells from human fetal testes and expansion of peritubular myoid cells in the presence of androgen. Reproduction 139: 749-757.

De Santa Barbara, P., N. Bonneaud, B. Boizet, M. Desclozeaux, B. Moniot, P. Sudbeck, G. Scherer, F. Poulat, P. Berta (1998) Direct interaction of SRY-related protein SOX9 and steroidogenic factor 1 regulates transcription of the human anti-müllerian hormone gene. Mol Cell Biol 18: 6653-6665.
Dym, M., M. Kokkinaki, Z. He (2009) Spermatogonial stem cells: mouse and human comparisons. Birth Defects Res C Embryo Today 87: 27-34.

Ehmcke, J., C.M. Luetjens, S. Schlatt (2005) Clonal organization of proliferating spermatogonial stem cells in adult males of two species of non-human primates, Macaca mulatta and Callithrix jacchus. Biol Reprod 72: 293-300.

Ehmcke, J., J. Wistuba, S. Schlatt (2006) Spermatogonial stem cells: questions, models and perspectives. Hum Reprod Update 12: 275-282.

Harley, V.R., M.J. Clarkson, A. Argentaro (2003) The molecular action and regulation of the testis-determining factors, SRY (sex-determining region on the $\mathrm{Y}$ chromosome) and SOX9 [SRY-related high-mobility group (HMG) box 9]. Endocr Rev 24: 466-487.

Jegou, B. (1992) The Sertoli cell. Baillieres Clin Endocrinol Metab 6: 273-311.

Koopman, P., M. Bullejos, J. Bowles (2001) Regulation of male sexual development by Sry and Sox9. J Exp Zool 290: 463-474.

Livak, K.J., T.D. Schmittgen (2001) Analysis of relative gene expression data using real-time quantitative PCR and the 2(-Delta Delta C(T)) method. Methods 25: 402-408. 
Loveland, K.L., S. Schlatt (1997) Stem cell factor and c-kit in the mammalian testis: lessons originating from Mother Nature's gene knockouts. J Endocrinol 153: 337-344.

Luetjens, C.M., G.F. Weinbauer, J. Wistuba (2005) Primate spermatogenesis: new insights into comparative testicular organisation, spermatogenic efficiency and endocrine control. Biol Rev Camb Philos Soc 80: 475-488.

Mackay, S., R.A. Smith (2007) Effects of growth factors on testicular morphogenesis. Int Rev Cytol 260: 113-173.

McLaren, T.T., P.M. Foster, R.M. Sharpe (1993) Effect of age on seminiferous tubule protein secretion and the adverse effects of testicular toxicants in the rat. Int J Androl 16: 370-379.

-Mitchell, R.T., G. Cowan, K.D. Morris, R.A. Anderson, H.M. Fraser, K.J. Mckenzie, W.H. Wallace, C.J. Kelnar, P.T. Saunders, R.M. Sharpe (2008) Germ cell differentiation in the marmoset (Callithrix jacchus) during fetal and neonatal life closely parallels that in the human. Hum Reprod 23: 2755-2765.

Morais da Silva, S., A. Hacker, V. Harley, P. Goodfellow, A. Swain, R. Lovell-Badge (1996) Sox9 expression during gonadal development implies a conserved role for the gene in testis differentiation in mammals and birds. Nat Genet 14: 62-68.

-Plant, T.M., G.R. Marshall (2001) The functional significance of FSH in spermatogenesis and the control of its secretion in male primates. Endocr Rev 22: 764-786.

Polanco, J.C., P. Koopman (2007) Sry and the hesitant beginnings of male development. Dev Biol 302: 13-24.

Rogatsch, H., D. Jezek, A. Hittmair, G. Mikuz, H. Feichtinger (1996) Expression of vimentin, cytokeratin, and desmin in Sertoli cells of human fetal, cryptorchid, and tumour-adjacent testicular tissue. Virchows Arch 427: 497-502.
Romano, F., A. Tripiciano, B. Muciaccia, P. De Cesaris, E. Ziparo, F. Palombi, A. Filippini (2005) The contractile phenotype of peritubular smooth muscle cells is locally controlled: possible implications in male fertility. Contraception 72: 294-297.

Rossi, F., A. Ferraresi, P. Romagni, L. Silvestroni, V. Santiemma (2002) Angiotensin II stimulates contraction and growth of testicular peritubular myoid cells in vitro. Endocrinology 143: 3096-3104.

Santiemma, V., F. Beligotti, M. Magnanti, S. Palleschi, L. Silvestroni, A. Fabbrini (1996) Endothelin-1 stimulates deoxyribonucleic acid synthesis and contraction in testicular peritubular myoid cells. Biol Reprod 54: 583-590.

Schell, C., M. Albrecht, C. Mayer, J.U. Schwarzer, M.B. Frungieri, A. Mayerhofer (2008) Exploring human testicular peritubular cells: identification of secretory products and regulation by tumor necrosis factor-alpha. Endocrinology 149: 1678-1686.

Schlatt, S., G.F. Weinbauer, M. Arslan, E. Nieschlag (1993) Appearance of alpha-smooth muscle actin in peritubular cells of monkey testes is induced by androgens, modulated by follicle-stimulating hormone, and maintained after hormonal withdrawal. J Androl 14: 340-350.

Schmittgen, T.D., K.J. Livak (2008) Analyzing real-time PCR data by the comparative $\mathrm{C}(\mathrm{T})$ method. Nat Protoc 3: 1101-1108.

Sharpe, R.M., H.M. Fraser, M.F. Brougham, C. McKinnell, K.D. Morris, C.J. Kelnar, W.H. Wallace, M. Walker (2003a) Role of the neonatal period of pituitary-testicular activity in germ cell proliferation and differentiation in the primate testis. Hum Reprod 18: 21102117.

Sharpe, R.M., C. McKinnell, C. Kivlin, J.S. Fisher (2003b) Proliferation and functional maturation of Sertoli cells, and their relevance to disorders of testis function in adulthood. Reproduction 125: 769-784.
Spinnler, K., F.M. Kohn, U. Schwarzer, A. Mayerhofer (2010) Glial cell line-derived neurotrophic factor is constitutively produced by human testicular peritubular cells and may contribute to the spermatogonial stem cell niche in man. Hum Reprod 25: 2181-2187.

Stukenborg, J.B., J. Wistuba, C.M. Luetjens, M.A. Elhija, M. Huleihel, E. Lunenfeld, J. Gromoll, E. Nieschlag, S. Schlatt (2008) Coculture of spermatogonia with somatic cells in a novel three-dimensional soft-agar-culture-system. J Androl 29: 312-329.

Swain, A., R. Lovell-Badge (1999) Mammalian sex determination: a molecular drama. Genes Dev 13: 755-767.

Tung, P.S., I.B. Fritz (1990) Characterization of rat testicular peritubular myoid cells in culture: alpha-smooth muscle isoactin is a specific differentiation marker. Biol Reprod 42: 351-365.

Viger, R.S., D.W. Silversides, J.J. Tremblay (2005) New insights into the regulation of mammalian sex determination and male sex differentiation. Vitam Horm 70: 387-413.

von Schonfeldt, V., H. Krishnamurthy, L. Foppiani, S. Schlatt (1999) Magnetic cell sorting is a fast and effective method of enriching viable spermatogonia from Djungarian hamster, mouse, and marmoset monkey testes. Biol Reprod 61: 582-589.

Weinbauer, G.F., H. Aslam, H. Krishnamurthy, M.H. Brinkworth, A. Einspanier, J.K. Hodges (2001) Quantitative analysis of spermatogenesis and apoptosis in the common marmoset (Callithrix jacchus) reveals high rates of spermatogonial turnover and high spermatogenic efficiency. Biol Reprod 64: 120-126.

Wistuba, J., A. Schrod, B. Greve, J.K. Hodges, H. Aslam, G.F. Weinbauer, C.M. Luetjens (2003) Organization of seminiferous epithelium in primates: relationship to spermatogenic efficiency, phylogeny, and mating system. Biol Reprod 69: 582-591.

Wistuba, J., J.B. Stukenborg, C.M. Luetjens (2007) Mammalian spermatogenesis. Func Dev Embryol 1: 99-116. 